\title{
Interfaces da Comunicação e da Educação na escola: a experiência do CAp-UFRJ em diálogo com alunos $\mathrm{e}$ professores $^{1}$
}

Beatriz Becker

Professora associada do Programa de Pós-Graduação e do Departamento de Expressões e Linguagens da Escola de Comunicação da Universidade Federal do Rio de Janeiro. E-mail: beatrizbecker@uol.com.br

Resumo: A visualidade eletrônica redimensiona as formas de visibilidade da cultura e produz modos distintos de socialização e de significação da experiência. O desenvolvimento e os usos das tecnologias digitais provocam transformações nas maneiras de ler, escrever e entender o mundo e impõem reflexões sobre desafios e potencialidades das interfaces da Comunicação e da Educação na formação escolar. Este trabalho busca identificar como alunos e professores do ensino médio compreendem a relevância da leitura crítica da mídia e de usos de tecnologias digitais em processos de aprendizagem e a pertinência da inserção ou não de uma disciplina sobre Comunicação e Jornalismo na formação escolar, a partir de pesquisa desenvolvida em parceria com o Colégio de Aplicação da Universidade Federal do Rio de Janeiro (CAp-UFRJ).

Palavras-chave: comunicação; jornalismo; mídia e educação; análise televisual; CAp-UFRJ.
Abstract: The electronic visuality resizes the forms of culture's visibility and produces distinct modes of socialization and signification of experience. The development and uses of digital technologies cause changes in how people read, write and understand the world and impose reflections on challenges and potentials of the interfaces of Communication and Education in school education. This work seeks to identify how high school students and teachers understand the importance of media critical reading and uses of digital technologies in learning processes, as well as the relevance of the insertion or not of a discipline about Communication and Journalism in school education, from a research conducted in partnership with the School of Application of the Federal University of Rio de Janeiro (CAp-UFRJ).

Keywords: communication; journalism; media and education; televisual analysis; Cap-UFRJ.
Recebido: 12/11/2016

Aprovado: 16/02/2017

1. Trabalho apresentado no GP Comunicação e Educação no XXXIX Congresso Brasileiro de Ciências da Comunicação. 
2. VAN DIJCK, J. The Culture of Connective. A Critical History of Social Media. Nova York: Oxford University Press, 2013.

3. ALBORNOZ, L. A. The International Fund for Cultural Diversity: A New Tool for Cooperation in the Audiovisual Field. International Journal of Cultural Policy. 2015. Disponível em: <www. tandfonline.com/doi/pdf/ 10.1080/10286632.2015.1 008467>. Acesso em: 9 abr. 2016

4. CURRAN, J. Media and Democracy. Londres: Nova York: Routledge, 2011.

5. BECKER, Beatriz. Mapeamento das pesquisas em Telejornalismo no Brasil: um estudo da produção acadêmico-científica de 2010 a 2014. Revista FAMECOS: mídia, cultura e tecnologia, v. 22, n. 4, 2015.

6. DUBOIS, P. Cinema, Vídeo, Godard. São Paulo: CosacNaify, 2004. e entretenimento. Porém, elas têm domínio sobre os protocolos dos processos de comunicação imersos em seus ambientes, tornando possível a manifestação de interesses de indivíduos e grupos diversos e coletando dados que monitoram o comportamento das pessoas. Assim, os consumidores ficam vulneráveis à vigilância de suas escolhas e de seus comportamentos na produção e consumo de mensagens como aponta José Van Dijck².

A internet e as redes sociais oferecem condições para o ativismo social em escala global, abrem espaço para o engajamento em causas sensíveis aos cidadãos e contribuem para a transformação social e interações diversas. Contudo, colaboram para a construção de valores que instigam conflitos em territórios físicos simbólicos e para ampliar o poder de grandes empresas de mídia. As indústrias culturais e de economia criativa distribuem cada vez mais conteúdos e serviços e, segundo Luis Albornoz ${ }^{3}$, a produção audiovisual no Brasil e no mundo exerce centralidade nesses mercados, reunindo alguns dos modelos de negócios mais rentáveis. A visualidade eletrônica redimensiona as formas de visibilidade da cultura e produz modos distintos de socialização e de significação da experiência. Os modelos tradicionais de transmissão televisiva desenvolvem modos simbióticos de relação com as mídias emergentes. Hoje, as transmissões de broadcast marcadas pela regularidade e pela simultaneidade, com programas organizados na grade de programação em horários e dias regulares que atingem grandes audiências dispersas em um mesmo momento, são apenas uma das opções de distribuição do conteúdo da TV. Há um incremento de consumo pautado pela lógica da livre circulação de conteúdos e formatos audiovisuais, sob sofisticados processos de regulação de transmissão de dados on demand. Muitas pessoas acessam vídeos através de dispositivos móveis em múltiplas plataformas e as emissoras de televisão aberta perdem espaço para serviços de vídeo por streaming. Suas audiências estão diminuindo ao longo dos anos, mas ainda são muito altas se comparadas com as demais mídias. A TV e os telejornais ainda exercem papel central no ambiente midiático na construção da realidade social cotidiana, e, como destacam Curran ${ }^{4}$ e Becker $^{5}$, são as principais fontes de informação sobre os acontecimentos sociais e de grande repercussão no Brasil e em outros países.

Porém, novas formas de narrativas em áudio e vídeo emergem no ambiente digital. As estéticas desses produtos audiovisuais, baseadas nas experiências do cinema e da televisão, manifestam hibridismo de linguagens e formatos inovadores nos quais o vídeo exerce um protagonismo - uma forma que pensa e que pensa não tanto o mundo quanto as imagens do mundo e os dispositivos que as acompanham, jogando com a dialética entre semelhança e dessemelhança, como demonstra Philippe Dubois ${ }^{6}$. O vídeo é um dos elementos mais recorrentes na produção noticiosa e na escrita contemporânea e tensiona os modos de representação dos acontecimentos, oferecendo conhecimentos sobre fatos relevantes, mas também hierarquizando atores e fatos sociais.

A visualidade se manifesta como recurso relevante de construção de sentido e a escrita com as palavras é apenas uma das maneiras possíveis de atribuir 
significações à vida social e aos acontecimentos. O desenvolvimento e os usos das tecnologias digitais provocam transformações nas maneiras de ler, escrever e compreender o mundo. Os processos de aprendizagem podem estimular um olhar seletivo de uma determinada imagem, para além dos elementos que se sobressaem em um determinado enquadramento escolhido pelo realizador, transformando o ver em agir e contribuindo para valorizar a relevante atuação do espectador na atribuição de sentidos aos textos. Assim, a educação deve avançar estimulando a interpretação dos textos midiáticos e a compreensão de que eles atribuem valores à experiência na contemporaneidade e direcionam a criação de vínculos e identidades. Em um momento em que as formas de pensar e perceber o mundo vêm sendo alteradas é fundamental atualizar a formação de estudantes e professores de diferentes disciplinas para linguagens, conteúdos e formatos audiovisuais, favorecendo o entendimento de áudios e vídeos noticiosos contemporâneos como mediações tecnológicas e culturais, como sugerem Burch $^{7}$, Rancière $^{8}$ e Becker ${ }^{9}$. A Comunicação pode colaborar para incentivar a integração e o diálogo com outras ciências na construção de saberes. Mas refletir sobre o próprio lugar da Comunicação e sobre o Jornalismo Audiovisual ${ }^{10}$ como forma de conhecimento na contemporaneidade, demanda superar a exclusiva compreensão da Comunicação e da mídia como um conjunto de transmissões de mensagens ou de dispositivos de informação, privilegiando mais o entendimento das interações decorrentes da ação de participar de algo, partilhar e pôr-se em comum dos processos comunicacionais, como afirma Sodré ${ }^{11}$.

O papel desempenhado pela mídia e pelo jornalismo é marcado por desafios e ambivalências na atualidade. A descentralização do poder coincide com a sua intensa concentração aparentemente sem limites. Deve-se compreender tanto os mecanismos de dominação que justificam e reproduzem o status quo quanto os mecanismos de resistência que podem forçar uma visão alternativa. Assume-se, que a dimensão criativa da educação é capaz de superar determinados costumes e funcionar como uma espécie de resistência à midiatização, em acordo com Sodré ${ }^{12}$. Proporcionar interações críticas e criativas com os textos midiáticos nas práticas pedagógicas implica entender o audiovisual como linguagem e forma de pensamento e desconstruir os modos como combinações de áudios e vídeos contam todos os dias histórias da vida social na convergência entre as mídias.

\section{CONSTRUINDO O OBJETO DE ESTUDO}

Este trabalho busca identificar como alunos e professores do ensino médio compreendem a relevância da leitura crítica da mídia e de usos de tecnologias digitais em processos de aprendizagem e a pertinência da inserção de uma disciplina sobre Comunicação e Jornalismo na formação escolar, a partir de pesquisa empírica desenvolvida durante quase nove meses com alunos e professores do Colégio de Aplicação da Universidade Federal do Rio de Janeiro
7. BURCH, N. Práxis do Cinema. São Paulo: Perspectiva, 2015.

8. RANCIÈRE, Jacques. Le spectateur émancipé. Paris: La Fabrique Éditions, 2008.

9. BECKER, B. Mídia, Telejornalismo e Educação. Matrizes: Revista do Programa de Pós-Graduação em Ciências da Comunicação da Universidade de São Paulo, São Paulo: ECA-USP, v. 10, n. 1, 2016.

10. Este conceito foi desenvolvido pela autora em pesquisa anterior por reconhecer que as narrativas jornalísticas audiovisuais veiculadas na TV e disponibilizadas na web sofriam influências mútuas. Disponível em: <http:// dx.doi.org/10.5007/1984-6924.2009v6n2p95>. Acesso em: 30 maio 2016.

11. SODRÉ, M. A Ciência do Comum. Notas para o método comunicacional. Petrópolis, RJ: Vozes, 2014.

12. SODRE, M. Reinventando a educação: diversidade, descolonização e redes. Petrópolis: Vozes, 2012. 
13. Agradeço a contribuição dos professores e alunos do CAp-UFRJ e da coordenação do setor de Língua Portuguesa do Colégio para o desenvolvimento desta investigação.

14. VILELA, R. S. Jóvenes y cultura audiovisual: nuevos modos de ver televisión. Revista Famecos, v. 23, n. 2, 2016.

15. MARTÍN-BARBERO, J. A comunicação na educação. São Paulo: Contexto, 2014.
(CAp-UFRJ), uma escola pública de referência no estado do Rio de Janeiro. É uma contribuição para fomentar o exercício da cidadania em processos de aprendizagem, por meio de interações críticas e criativas com a mídia e com conteúdos e formatos audiovisuais noticiosos no ambiente digital, a partir da contribuição de alunos e professores do CAp-UFRJ' ${ }^{13}$.

Na sociedade contemporânea, a competência comunicativa e a construção do conhecimento passam por um domínio dos códigos audiovisuais capaz de oferecer possibilidades de interpretações diferentes do que aparece nas telas da TV e do computador e da realidade do mundo fora delas. As dimensões teórico-metodológicas do campo da Mídia e Educação e da Análise Televisual permitem reconhecer que mensagens, narrativas e notícias que utilizam a linguagem audiovisual são constituídas por modos de dizer e de intervir na vida social, e seus efeitos de sentidos também dependem da maneira como se interage com a TV e como se usa o computador, a internet e as mídias sociais. Entender a maneira como os jovens interagem com a cultura audiovisual, estabelecendo formas singulares de interação com o ininterrupto fluxo de imagens na multiplicidade de telas, é uma forma de elaborar ferramentas para se aproximar dos universos da infância e da juventude em processos de aprendizagem e trazer para dentro da escola formas inovadoras de construção de conhecimentos sobre a realidade social em diferentes linguagens e sob diferentes ângulos, como também apontam Vilela ${ }^{14}$ e Martín-Barbero ${ }^{15}$.

A metodologia adotada nesta investigação foi constituída por quatro etapas: contato e conversações com os professores do Colégio de Aplicação da UFRJ; elaboração de um questionário como instrumento de pesquisa a ser aplicado com alunos do ensino médio submetido previamente à apreciação da coordenação do setor de língua portuguesa da escola e aberto às suas contribuições; construção de um segundo questionário direcionado aos professores deste setor; e análise e sistematização dos resultados. Participaram da pesquisa mais de $50 \%$ dos alunos do ensino médio da escola, um total de 164 alunos de sete turmas: três do primeiro ano, duas do segundo ano e duas do terceiro ano (21A, 21B, 21C, 22A, 22C, 23B, 23C). O primeiro questionário foi impresso e aplicado presencialmente com o objetivo de compreender como os estudantes percebem a relevância ou não da utilização das mídias para a construção de conhecimentos na escola e os estudantes escreveram as respostas em suas salas de aulas. Outro questionário foi respondido on-line pelos professores sobre a mesma temática para que fosse possível refletir sobre a pertinência ou não de uma disciplina sobre Comunicação e Jornalismo na grade curricular, a partir de suas inquietações e experiências.

Questiona-se se as apropriações das tecnologias digitais, a Comunicação e o Jornalismo podem colaborar para práticas pedagógicas e relações de ensino e aprendizagem inovadoras, amparadas pelas contribuições dos campos da Mídia e Educação e da Análise televisual. Os dados dos questionários foram sistematizados por meio de análise quantitativa e qualitativa. Em uma primeira fase, foram contabilizadas todas as respostas positivas e negativas de cada turma 
referentes às 13 perguntas do questionário direcionado aos alunos para formulação dos primeiros resultados. Essas respostas demonstraram que a maioria dos alunos utiliza a internet para se informar, principalmente através do celular e do computador. Porém, elas também indicam que a televisão ainda é um meio muito presente na vida dos estudantes do ensino médio: 100\% dos alunos responderam que é necessário saber o que acontece no Brasil e no mundo para o desenvolvimento da capacidade crítica. A compreensão dos fatos sociais ajuda a ampliar a visão de mundo deles e possibilita a conexão entre culturas diversas. Os alunos argumentaram que o jornalismo é importante porque mantém a sociedade informada e esse conhecimento interfere na formação da população. Entretanto, ressaltaram que a mídia estabelece relações de poder, controla o que é transmitido para o público sem revelar os diferentes lados das histórias contadas e influencia as pessoas.

O estudo das maneiras que os estudantes atribuem sentidos aos noticiários televisivos foi realizado na segunda fase desta pesquisa e correspondeu à análise qualitativa. A interpretação dos dados foi viabilizada por meio da construção de tabelas que indicavam o nível de envolvimento e de interesse dos alunos em relação a cada uma das questões propostas, com a transcrição das suas opiniões. A partir da leitura das respostas dos estudantes das sete turmas foi gerada uma síntese de suas opiniões por turma. As respostas mais expressivas foram destacadas, as sínteses de cada uma das turmas foram comparadas e uma nova síntese das respostas de todas as turmas foi construída. Assim, foi possível refletir sobre o conjunto das respostas de todos os entrevistados. Os resultados alcançados são sistematizados abaixo.

\section{VOZES DOS ESTUDANTES E DOS PROFESSORES}

Os alunos tendem a realizar uma leitura crítica dos conteúdos e formatos audiovisuais da mídia e manifestaram aspectos positivos e negativos sobre a linguagem do telejornal. Eles afirmam que a informação é transmitida de uma forma simples de compreender os acontecimentos importantes, é dinâmica e "o estímulo visual é o melhor jeito de passar a informação e tocar o telespectador”. Mas os alunos ressaltam que o telejornal quase sempre mostra assuntos de um jeito que favorece as emissoras e deixa de fazer certas críticas importantes sobre, por exemplo, questões políticas. "Sempre há uma ideologia representada pela linguagem em que se transmite a notícia”, disse um aluno do $3^{\circ}$ ano da turma 23C. "Sempre existirá um ponto de vista de quem está contando; então cabe a cada um avaliar o que ouviu e construir seu conhecimento com diversas fontes e pontos de vista”, afirmou outro estudante da turma $22 \mathrm{~A}$ do $2^{\circ}$ ano.

Contudo, a possibilidade de produzir um telejornal dos próprios estudantes na escola mobilizou o interesse de pouco mais de 1/3 do total dos respondentes. Eles destacaram que esta atividade ajudaria a compartilhar informações que são necessárias para a formação de um indivíduo sem preconceitos e atualizado, 
ampliar conhecimentos, construir consciência crítica, auxiliar a construção de debates, aprender como as informações são coletadas e divulgadas e as notícias são veiculadas, integrar alunos e turmas e "ficar mais antenado no mundo e no que acontece na escola também”, como declarou um aluno do $2^{\circ}$ ano da turma 22A. Um integrante do $3^{\text {o }}$ ano da turma 23B, disse: "Atualmente existe um minijornal no CAp, mas acho importante o contato com novas mídias, [...] as pessoas mais novas aprenderiam a usar a tecnologia de uma forma mais responsável". A possibilidade de experimentar uma nova linguagem também despertou o interesse de outros alunos como um incentivo maior à pesquisa e à busca por fontes capazes de provar a veracidade dos fatos. Porém, se a maioria deles demonstrou interesse pela possibilidade de produção de um telejornal na escola, não considerou esta atividade relevante.

Os estudantes reconhecem que os modos como interagem com os textos da mídia se tornam mais autônomos e interpretativos a partir de conhecimentos que constroem nas aulas de redação. Eles demonstraram interesse pelo aprendizado da escrita. Uma das alunas da turma 21A do $1^{\circ}$ ano afirmou: "Nessas aulas eu consigo aprender como o mundo está organizado e a entendê-lo melhor". Outra estudante do $3^{\circ}$ ano, da turma 23B disse: "Ajuda a organizar a minha linha de pensamento, conhecer e debater novos assuntos e a tirar 1000 no ENEM". Os alunos apontam a relevância dessas aulas para a compreensão de acontecimentos importantes, a construção de argumentos próprios, o entendimento de posicionamentos diferentes e para questionar as histórias que estão sendo contadas. Aprendem a escrever textos coerentes sobre temas atuais relevantes para a sociedade brasileira e questionam como podem contribuir para melhorar uma situação ou realidade. Mas sinalizam que os assuntos mais discutidos nem sempre são aprofundados porque o principal objetivo das aulas é ensinar a escrever uma redação da melhor forma para passar no concurso.

Quando questionados sobre a relevância da utilização da mídia nas aulas e em outras atividades na escola, os estudantes destacaram que esta ação poderia ajudá-los a entender o mundo à sua volta; tornar o aprendizado mais interessante e interativo; integrar o conhecimento da escola com o cotidiano e relacionar o conteúdo das matérias com a atualidade; questionar se o que a mídia mostra é o real e perceber se há manipulação ou criação de estereótipos; colaborar para tornar os adolescentes politicamente ativos e tomar contato com outros meios de expressão além das palavras. Uma aluna da turma 22C do $2^{\circ}$ ano inferiu: "se a mídia está presente em nossas vidas todos os dias, por que não falar sobre isso na escola?”. Os estudantes apreciam os professores que mostram documentários e trazem materiais didáticos multimídia para as aulas, o que contribui para a compreensão da matéria. Porém, eles consideram que nem sempre a infraestrutura da escola permite a utilização das mídias nas aulas e em atividades extracurriculares, o que não favorece o uso de códigos diferentes do que a palavra para a escrita e a expressão.

Os alunos identificam que o maior problema de escassez de meio de comunicação nas escolas é a falta de verbas. Afirmam que embora a escola 
possua aparelhos de televisão e computadores, eles são precários, falta funcionários para orientar o acesso dos alunos a esses instrumentos, a internet só está disponível na sala de informática e nem sempre funciona. Assim, são orientados a utilizarem os meios de comunicação apenas para a realização de trabalhos específicos e os professores tendem a optar por aulas mais tradicionais. Os estudantes também afirmam que o curto tempo disponível na grade curricular para acessar a TV e internet não colabora para os usos das mídias na escola, uma vez que a carga horária escolar é muito condensada. Entendem que a escola, como instituição, não está preparada para interagir com inovações do mundo contemporâneo, como afirma um aluno da turma 22A do $2^{\circ}$ ano.

O questionário direcionado aos professores foi constituído por oito perguntas e respondido por 1/3 dos professores efetivos do setor de língua portuguesa do CAp-UFRJ, responsável pelos conteúdos de linguagem e expressão. Foi possível aferir em caráter exploratório como os professores entendem as relações entre Comunicação e Educação e suas possíveis contribuições para a renovação de processos de aprendizagem na formação escolar capazes de interagir com a cultura das mídias para a promoção do exercício da cidadania. A transição de produção e uso de linguagens na construção de conhecimentos no mundo não é reconhecida como uma novidade exclusiva da contemporaneidade pelos professores do CAp-UFRJ que participaram desta pesquisa. Um deles afirma que as mudanças nas formas de escrita resultam das novas maneiras de mediação do conhecimento pelas tecnologias digitais, mas ressalta que o uso de novas linguagens não deve significar o abandono ou a depreciação das antigas.

Os professores respondentes afirmam que recorrem à utilização de outros códigos além das palavras e tipos de textos para propor reflexões críticas aos alunos, como uma estratégia produtiva para se aproximarem da realidade do aluno, mostrarem que os conhecimentos que constroem em sala estão diretamente ligados às suas demandas cotidianas e que diferentes tipos de textos podem ajudá-los a ampliar o entendimento do mundo. Eles percebem que o interesse dos alunos do ensino médio por usos das mídias nos processos de aprendizagem é cada vez maior e que essa prática pode colaborar para a elaboração de propostas de intervenção solidária na realidade, respeitando os valores humanos e considerando a diversidade sociocultural.

Os docentes revelam que, muitas vezes, os próprios alunos lhes trazem a demanda pela utilização de mídias na escola. Mas um desses docentes afirma que falta formação aos professores para que eles possam se apropriar de tais mídias de forma mais eficaz em sala de aula, bem como de incentivo material, em termos de equipamentos e tecnologias, para um melhor proveito do uso das mídias no ensino básico público. Eles entendem que a mídia deve ser percebida como um ambiente a ser explorado para a construção de conhecimentos e as informações jornalísticas sobre o Brasil e o mundo são pertinentes para a formação dos alunos por fazerem parte do seu cotidiano, sendo importantes elementos na construção de discursos individuais e coletivos e permitindo aos alunos visão crítica e reflexiva da realidade. 
Um dos respondentes afirmou que essa prática auxilia os alunos a compreender, relacionar e interpretar informações, fatos, opiniões e argumentos em defesa de um ponto de vista. Contudo, os docentes sugerem que os usos das mídias devem ser associados às demais disciplinas curriculares e não devem ser integrados à grade curricular como mais uma disciplina autônoma. Outro professor destacou que o aluno deve trabalhar as diferentes funções da linguagem; o que já é abordado na disciplina de língua portuguesa. Assim, as disciplinas já existentes poderiam dar conta dos conteúdos que pudessem vir a compor a ementa dessa nova disciplina.

Entretanto, os professores que participaram desta pesquisa acreditam que o incremento do diálogo entre a Comunicação e a Educação pode contribuir para a qualificação das práticas pedagógicas na atualidade e para a atualização dos docentes. As interfaces entre a Comunicação e a Educação poderiam resultar em ações capazes de contribuir com a formação de cidadãos críticos. No contexto da reforma curricular, os professores ainda consideram o currículo e a avaliação questões centrais e destacam a necessidade de valorizar conceitos de diferentes áreas do conhecimento na formação dos estudantes, inclusive reflexões sobre os modos de incorporação das mídias em ações em sala de aula que já fazem parte do cotidiano dos alunos.

\section{CONSIDERAÇÕES FINAIS}

Este trabalho buscou refletir sobre interfaces da Comunicação e da Educação na escola, a partir da experiência do CAp-UFRJ, em diálogo com alunos e professores, sem pretensão de esgotar este debate. A discussão aqui proposta para os estudos de Comunicação e Educação em práticas pedagógicas, considerando contribuições das dimensões teórico-metodológicas do campo da Mídia e da Educação e da Análise Televisual, pode estimular e favorecer: o domínio relativo de formas emergentes de leitura e escrita na escola; a atualização da formação de novos professores; a construção de uma consciência autônoma para a interpretação do mundo nos processos de aprendizagem; uma intervenção crítica e criativa pelos cidadãos na vida social e na mídia; a ampliação e complementação de conteúdos escolares sobre atualidades, contribuindo para a qualidade da formação dos estudantes com atenção aos seus próprios usos das tecnologias digitais.

Os estudos de mídia e educação podem propor novas estratégias e metodologias de ensino e avaliação aos docentes e colaborar para uma integração interdisciplinar que enriquecerá o processo de construção do conhecimento do aluno, o que não requer, necessariamente, a inclusão de uma disciplina específica sobre Comunicação e Jornalismo na grade curricular. Tanto os professores quanto os alunos do CAp-UFRJ identificam qualidades e limitações na formação escolar. Os estudos de Mídia e Educação não devem deixar de considerar as restrições e potencialidades inerentes ao contexto socioeconômico e cultural 
onde as diversas práticas pedagógicas estão inseridas, ao proporem renovações e percursos metodológicos capazes de auxiliar a atualização dos docentes e a formação de novos professores. A Comunicação também enfrenta desafios e oportunidades de contribuir para leituras críticas da mídia e das narrativas jornalísticas audiovisuais nos diálogos possíveis a serem estabelecidos com a área da Educação.

\section{REFERÊNCIAS BIBLIOGRÁFICAS}

ALBORNOZ, L. A. The International Fund for Cultural Diversity: A New Tool for Cooperation in the Audiovisual Field. International Journal of Cultural Policy. 2015. Disponível em: <www.tandfonline.com/doi/pdf/10.1080/1028 6632.2015.1008467>. Acesso em: 9 abr. 2016.

BECKER, B. Mídia, Telejornalismo e Educação. Matrizes: Revista do Programa de Pós-Graduação em Ciências da Comunicação da Universidade de São Paulo, São Paulo: ECA-USP, v. 10, n. 1, 2016.

- Mapeamento das pesquisas em Telejornalismo no Brasil: um estudo da produção acadêmico-científica de 2010 a 2014. Revista FAMECOS: mídia, cultura e tecnologia, v. 22, n. 4, 2015. Disponível em: $<$ http:/ / revistaseletronicas. pucrs.br/ojs/index.php/revistafamecos/article/view/20534>. Acesso em: 13 abr. 2016.

BURCH, N. Práxis do Cinema. São Paulo: Perspectiva, 2015.

CURRAN, J. Media and Democracy. Londres; Nova York: Routledge, 2011.

DUBOIS, P. Cinema, Vídeo, Godard. São Paulo: CosacNaify, 2004.

MARTÍN-BARBERO, J. A comunicação na educação. São Paulo: Contexto, 2014.

RANCIÈRE, Jacques. Le spectateur émancipé. Paris: La Fabrique Éditions, 2008.

SODRÉ, M. A Ciência do Comum. Notas para o método comunicacional. Petrópolis, RJ: Vozes, 2014.

- Reinventando a educação: diversidade, descolonização e redes.

Petrópolis: Vozes, 2012.

VAN DIJCK, J. The Culture of Connective. A Critical History of Social Media. Nova York: Oxford University Press, 2013.

VILELA, R. S. Jóvenes y cultura audiovisual: nuevos modos de ver televisión. Revista Famecos, v. 23, n. 2, 2016. 